\title{
PROMOTING ETHICAL PRACTICES IN ENGINEERING UNDERGRADUATES
}

\author{
Manuel F. Silva*,1,2 ${ }^{*}$ Benedita Malheiro ${ }^{1,2}$, Paulo Ferreira $^{1}$ and Pedro Guedes ${ }^{1}$ \\ ${ }^{1}$ Instituto Superior de Engenharia do Porto, Politécnico do Porto \\ Rua Dr. António Bernardino de Almeida, 431 \\ 4249-015 Porto, Portugal \\ *E-mail:mss@isep.ipp.pt \\ www.isep.ipp.pt \\ ${ }^{2}$ INESC TEC, \\ Campus da Faculdade de Engenharia da Universidade do Porto \\ Rua Dr. Roberto Frias \\ 4200-465 Porto, Portugal
}

\begin{abstract}
Future engineering professionals are expected to be technically and scientifically sound, work in international and interdisciplinary teams and, above all, be able to systematically adopt sustainable and ethical design and development practices. These are the challenges faced nowadays by engineering undergraduates and engineering programmes. The European Project Semester (EPS) is a capstone programme offered by a network of European universities to engineering, project design and business undergraduates. Its goal is to prepare engineering undergraduates for their future profession by exposing them to one semester of project-based, multicultural and multidisciplinary teamwork where both hard and soft skills are matured. The Portuguese programme, which is run by Instituto Superior de Engenharia do Porto (ISEP) since the academic year of 2010-2011, emphasises additionally on the ethical and sustainability dimensions of engineering project development. This paper describes how EPS@ISEP achieves this goal by introducing the programme, defining and applying an analysis framework to illustrative robotic projects developed within the programme, identifying and collecting evidences of ethical design and development practices.
\end{abstract}

Keywords: Engineering Education; Engineering Capstone Programme; Ethics; Project-based Learning; Robotics.

\section{Introduction}

The challenge faced by engineers is to design ingenious solutions to problems afflicting individuals or the society, improving the overall well-being (ethical design) and minimising the usage of the planet's resources (sustainable design). However, engineering professionals must decide and act based on what is known, and what is known is incomplete. To make fair decisions, engineers must use ethics when knowledge is unavailable - ethics can, therefore, be seen as a behavioural code to handle difficult or conflicting scenarios. The set of moral values - ethics - of any culture, namely the notion of right and wrong, are imprinted by family, school and society since infancy. Professional ethics tend to be mostly an extension of personal ethics. ${ }^{1}$

Ethics, as a whole, deals with the personal moral choices made when interacting with others, including those made while practising engineering. Specifically, engineering ethics encompasses not only all decisions taken within the engineering practice. Thus, engineering ethics is a body of philosophy indicating how engineers should conduct themselves in their professional capacity. ${ }^{2}$ Whether working on multinational project teams, navigating geographically dispersed supply chains, or engaging customers and clients abroad, engineering graduates encounter worlds of professional practice that are increasingly global in character. ${ }^{3}$ In this context, the global engineer needs to be aware of effective ways to navigate these cultural differences, which is crucial for achieving their common goals. ${ }^{4}$ This makes a 
strong case in favour of using multinational team work as a set up to learn socio-professional ethics. When students communicate, discuss or organise their project work, they learn to respect the values of others and develop global engineering competency. ${ }^{3}$

Development of ethical behaviour skills in future engineers is a key competency for engineering schools as ethical behaviour is a part of the professional identity and practice of engineers. ${ }^{5}$ The problem is that standard engineering degrees assume that knowledge is complete, i.e., students are provided with all the formulas, techniques and procedures to solve the given problems. This is still the case of typical professional internships and capstone projects were all requirements, tools and tasks are pre-defined. However, when developing open-ended projects, students are frequently faced with lack of expertise and incomplete domain knowledge. This latter scenario is what is expected of future engineering professionals - solve complex unknown problems on behalf and for the well-being of mankind. Consequently, higher education institutions need to train engineering undergraduates to ethically address these future challenges.

Capstone projects, in particular, allow engineering students to apply and expand their knowledge and soft skills collaboratively, while addressing a real world problem. In a closed project there is already the definition of what will be done and the tools that will be used, only the details are missing. On an open project there is the need to define what will be done, how it will be done, and also why it will be done. This way it will be an ethics, and not only a technological, decision.

From a different perspective, ethics is also needed to provide engineering education for sustainable development. The society is becoming aware that resources are finite - if they were infinite, we could use them without thinking, but as the resources are finite, we must think before using them. As people don't know the resources that will be needed in the future, or how they will be needed, it is not possible to base our decisions only on science - ethics must also be used. Therefore, teaching sustainability is a good way to teach ethics, without mentioning the name ethics.

Given these ideas, after this introduction, Section 2 introduces the requirements of Engineering Education, in particular in the area of Ethics and Sustainability. Next, section 3 briefly introduces the European Project Semester and is followed by Section 4 that describes the implementation of the program at the School of Engineering of the Polytechnic of Porto (EPS@ISEP). Section 5 introduces some examples of projects in robotics developed in the scope of EPS@ISEP and is followed by Section 6 were is discussed how the EPS@ISEP students consider the ethical aspects during the development of their projects. The paper ends with some concluding remarks on Section 7 .

\section{Undergraduate Engineering Ethics}

Traditionally, professional ethics instruction in engineering is commonly conducted by examining case studies in light of the code of conduct of a suitable professional body. ${ }^{1}$ In the last decade, the development of ethical and sustainable design and development practices in engineering undergraduates has become a pervasive goal of engineering education due to pressing environmental and ethical problems such as global warming and autonomous intelligent systems. Several academic societies like the Institute of Electrical and Electronics Engineers (IEEE), the Association of Computing Machinery (ACM) or the American Association for the Advancement of Artificial Intelligence (AAAI) have been actively working to define references, guidelines

Professional engineering bodies like the Royal Academy of Engineering and the Engineering Council joined efforts in 2017 and defined a common Statement of Ethical Principles for the engineering profession to clarify "what it means to behave in an ethically responsible 
way". The identified principles are "embedded at all stages of professional development for engineers and those technicians, tradespeople, students, apprentices and trainees engaged in engineering. It is equally important for anyone who manages or teaches engineers to be aware of these principles, even if they themselves are not an engineer". They state that "Engineering professionals work for the wellbeing and safety of our society so it is vital that they maintain and promote high ethical standards. They also have a responsibility to challenge unethical behaviour wherever they see it." 6

Several national and international engineering accreditation organisations and engineering professional bodies around the world have disclosed the criteria that should be followed by high education institutions graduating engineers, and these include ethics. The EURACE® Standards and Guidelines for Accreditation of Engineering Programmes, from European Network for Accreditation of Engineering Education, claims that judgement making enables the "ability to gather and interpret relevant data and handle complexity within their field of study, to inform judgements that include reflection on relevant social and ethical issues, to identify, formulate and solve engineering problems in their field of study as well as to manage complex technical or professional activities or projects in their field of study, taking responsibility for decision making". 7 The Engineering Council defines for an engineering degree to be accredited in UK, six broad areas of learning are analysed: $(i)$ science and mathematics; ( $i i)$ engineering analysis; ( $i i i)$ design; ( $i v$ ) economic, legal, social, ethical and environmental context; $(v)$ engineering practice; and $(v i)$ general skills. ${ }^{8}$ ABET in the United States defines a set of standards, called the Engineering Criteria 2000 (EC2000), ${ }^{9}$ for engineering degrees. EC2000 shifted the basis for accreditation from inputs - what is taught - to outputs - what is learned - with the introduction of programme outcomes criteria. ${ }^{10}$ The aim of these criteria is to ensure that students attain an understanding of professional and ethical responsibility as well as the broad education necessary to understand the impact of technical solutions in a global, economic, environmental and societal context. Engineers Australia, defines that engineering graduates must demonstrate at the point of entry to practice, among other set of competencies, ethical conduct, professional accountability and professional management and conduct. ${ }^{11}$

Furthermore, when launching the Statement of Ethical Principles for the engineering profession, the Royal Academy of Engineering stated that "Engineering professionals work for the well-being and safety of our society so it is vital that they maintain and promote high ethical standards. They also have a responsibility to challenge unethical behaviour wherever they see it." and added that "With this clear statement of what it means to behave in an ethically responsible way, the profession needs to ensure that the principles are embedded at all stages of professional development for engineers and those technicians, tradespeople, students, apprentices and trainees engaged in engineering. It is equally important for anyone who manages or teaches engineers to be aware of these principles, even if they themselves are not an engineer." 12

\section{The European Project Semester Framework}

The European Project Semester is a one semester student-centred international capstone programme started in 1995 by Arvid Andersen. ${ }^{13}$ EPS provides an integrated framework for undertaking engineering capstone projects, which adopts a project-based learning methodology, focuses on teamwork and exposes students to cultural, scientific and technical diversity. In fact, it was designed for the capstone semester of engineering, product design and business degrees. EPS aims to prepare future engineers to think and act globally. ${ }^{14}$

Currently it is offered by a group of 19 higher education institutions (the EPS providers), 
as part of their student exchange programme portfolio ${ }^{a}$. EPS Providers have the freedom to implement the programme with distinct "flavours", while complying with the EPS 10 Golden Rules a, which include: English is the working language; teams must be formed by students from different countries; it is worth 30 ECTU credit units (ECTU), consisting of a multidisciplinary project and a set of project supportive courses, devoted to soft skills (languages, team building, project management).

The EPS is a package organised around one central module - the EPS project - and a set of complementary supportive modules. The project proposals refer to multidisciplinary real world problems, i.e., draw on knowledge from diverse fields, and are open-ended, i.e., specify exclusively top level requirements such as the compliance with the applicable directives/norms and the budget. According to the EPS 10 Golden Rules, the teams, which are composed of four to six students from different scientific backgrounds and nationalities, are fully responsible for the development of their projects..$^{15}$ Multicultural and multidisciplinary educational backgrounds contribute to product development and innovation, development of communication skills and catalyse collaborative learning among team elements.

EPS prepares students for lifelong learning by offering complex multidisciplinary projects, facilitators rather than supervisors, and by fostering student autonomy, multicultural teamwork, problem-solving and critical thinking. In particular, the structure of the program allows students to focus and reflect on an open-ended project from different perspectives, including the technical-scientific state of the art, ethics, sustainability, marketing, communication and project management. The acquisition of ethical and sustainable development competencies is achieved by offering challenging sustainability-driven projects, seminars and activities to raise students' awareness and promote knowledge regarding the adoption of sustainable perspectives adapted to the specificities of each project. Considering that sustainable thinking was identified as one of the key transversal competencies that an engineer must acquire, a program like this one can contribute to arousing this sensitivity among engineering students, by encouraging them to develop projects related to sustainable issues and to approach this multifaceted concept from a variety of perspectives.

\section{The European Project Semester at ISEP}

The EPS@ISEP programme - the EPS provided by the School of Engineering - Instituto Superior de Engenharia do Porto - of the Porto Polytechnic - welcomes engineering, business and product design students since 2011. It is a 30 ECTU engineering capstone programme composed of six modules: Project, Project Management and Team Work, Marketing and Communication, Foreign Language, Energy and Sustainable Development and Ethics and Deontology. The two ECTU modules are project supportive seminars oriented towards the specificities of each team project. In particular, the Ethics and Deontology modules, which runs in weeks 2-7 makes the students perform the study, selection, application and reporting of applicable codes of ethics in order to derive product requirements. The results are presented in the chapter "Ethical and Deontological Concerns", of their project report.

As far as project supervision is concerned, EPS@ISEP adopts a unique model where a panel of multidisciplinary expert advisers acts as a coaching and consulting committee. Concerning communication, the panel is aware that it is interacting with students from diverse scientific and cultural backgrounds. Furthermore, in the weekly supervision meeting only the topics previously specified by the team in the wiki agenda are discussed. Another very important aspect of the coaching methodology is the prompt feedback given to the students. Students meet with the panel once a week to discuss the topics the team has

${ }^{\mathrm{a}} \mathrm{http}$ ///www.europeanprojectsemester.eu/ 
previously posted in the wiki agenda. During the semester, the teams maintain the project wiki and produce several deliverables, including the report, video, paper, manual, brochure and proof of concept prototype.Figure 1 illustrates this process.

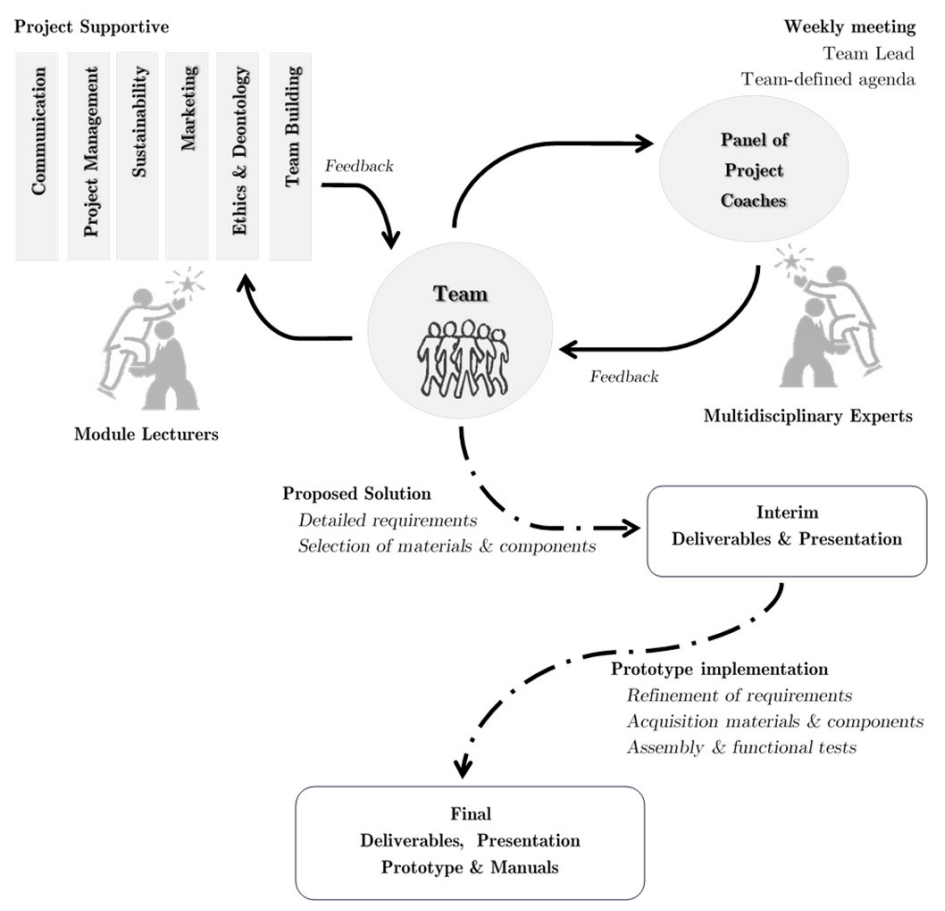

Fig. 1. EPS@ISEP learning process ${ }^{16}$

EPS@ISEP contributes to the development of: $(i)$ critical thinking \& problem solving by specifying open-ended project proposals, promoting inner team brainstorms and weekly meetings with a group of multidisciplinary coaches; (ii) effective communication by fostering inter-cultural and professional communication skills - the preparation of multiple textual and media deliverables during the semester and the definition of the agenda, leading, reporting the achievements and writing the minute of the weekly project meeting with the panel of advisers; (iii) collaboration and team building by working together in multicultural and multidisciplinary teams; (iv) creativity $\&$ innovation by being expose to ill defined open-ended problems, i.e., with very general requirements such as the budget, the applicable European Union (EU) directives and the adoption of the International System of Units; $(v)$ socio-professional ethics by tackling the related aspects of the project within the ETHDO module, with the writing of a dedicated report chapter, and PROJE module, with the establishment of associated project requirements; and (vi) sustainable development by addressing all aspects related within the ESUSD and PROJE modules, resulting in the writing of a dedicated report chapter and the identification of related project requirements, respectively.

\section{Examples of Robots Developed During the EPS@ISEP}

In this section are presented three examples of biological inspired robots developed by teams of students enrolled on EPS@ISEP. The design and development of biologically inspired robots allows the students to fulfil the previously described requirements and objectives and, as a result, is common the adoption of these projects within the EPS@ISEP project 
capstone module for the benefit of engineering students. The ethical aspects considered by the students during the development of these projects are discussed in the following section

\subsection{Flying Bird}

During the EPS@ISEP spring of 2014 edition a team composed of four students, with different nationalities and backgrounds developed an ornithopter (a biological inspired flying robot). The main goal was to create a robot that could fly up and land safely without a propeller, within a budget of $250 €$.

During the state of the art study the team identified a number of different solutions to make the ornithopter fly and it was decided to implement a biplane. ${ }^{17}$ After some conceptual studies, the complete ornithopter (including the wings, mechanical structure, and detailed actuation system) was designed in SolidWorksTM, as depicted in Figure 2a (left), and were performed some detailed computations regarding the lift and drag forces involved in the flight of the apparatus. ${ }^{17}$ These studies lead to the implementation of "MyBird", depicted in Figure 2b (right), with the following characteristics: $(i)$ a body $30 \mathrm{~cm}$ long by $7 \mathrm{~cm}$ wide (in the widest section); ( $i$ i ) a wingspan of $50 \mathrm{~cm}$ (when the wings are positioned horizontally); (iii) a flapping frequency of 11 flap/s; (iv) a weight of approximately $100 \mathrm{~g}$; and $(v)$ a power autonomy of $10 \mathrm{~min} .^{17}$

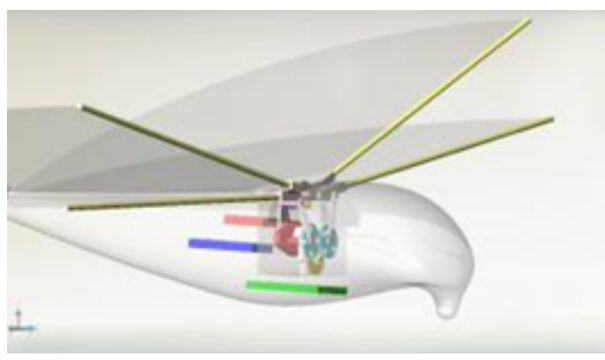

(a)

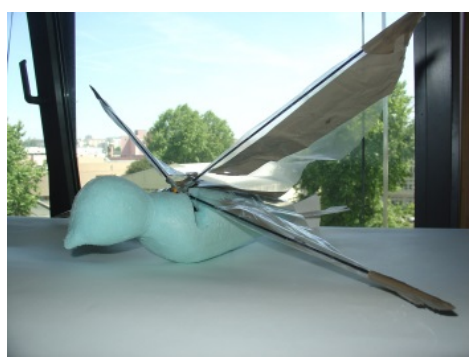

(b)

Fig. 2. Image of the biological inspired Flying Bird. ${ }^{17}$

\subsection{BroFish}

Another biological inspired robot project developed during the EPS@ISEP spring of 2014 edition was the BroFish. This swimming robot project was also developed by a team of four students, with different nationalities and backgrounds.

BroFish was envisioned by the team to be a construction kit targeted to kids aged between eight and twelve. ${ }^{18}$ It should be used as a learning tool, covering three different fields (mechanics, robotics and programming) and allowing experimenting with several customizable parts (tail, fins and programming packages). In the adopted architecture design, depicted on Figure 3 (left), the robot has one back fin, two pectoral fins at the side of the body and an additional fin at the bottom of the robot for steering purposes. The back fin is used for propulsion - an approach identical to the natural locomotion of fish - rather than the pectoral fins. In order to propel the robot with an oscillating back fin, the team decided to transfer the continuous rotation of a Direct Current (DC) motor into a swinging tail movement rather than using a servomotor. The final architecture design of the biologically inspired robot was simulated using a 3D design software (Figure 3, left). After selecting suitable components [26], a prototype was implemented (Figure 3, right). Tests in the pool revealed the potential of the new tail mechanism to effectively propel the robot forward. ${ }^{18}$ 


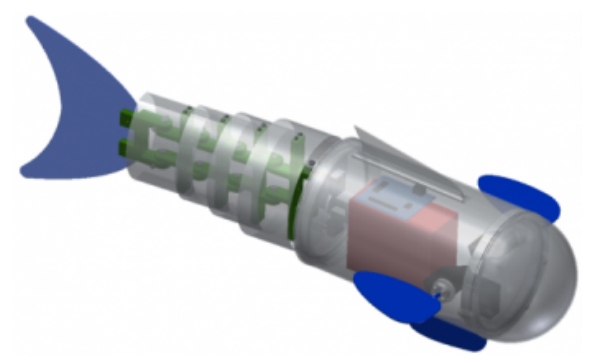

(a)

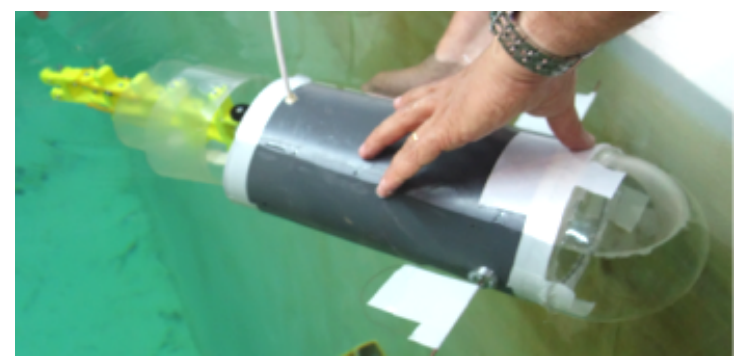

(b)

Fig. 3. Image of the biological inspired BroFish. ${ }^{18}$

\subsection{Bubbles}

Bubbles is a didactic robotic fish intended to appeal young children and provide an appropriate mix of fun and educational learning, allowing to teach young children the basics of programming. ${ }^{19}$

The body shape is based on that of a typical wider body of ostraciiform fish, such as the box fish and the puffer fish. It is approximately $150 \mathrm{~mm}$ long and with a compartmentalized interior, designed to house all of the fish's electronic components (Figure 4a, left). The design was created in Siemens NXTM10. The main body consists of a top and bottom piece, connected via bolts and separated by a waterproof gasket. The body is 3D printed using polylactic acid (PLA). The motion of the fish is provided by a servo motor connected to the rear fin drive axis via springs. The springs dampen the motion and help to prevent component damage from repetitive stress. The axis, which is split into two sections to allow for simple disassembly, leaves the interior of the fish through holes water-proofed with Orings (Figure $4 \mathrm{~b}$, centre). The control of movement is dictated by an Arduino Nano which is programmed by the user, using a customised block-based programming language developed from the open source-basis of ArduBlock. ${ }^{19}$

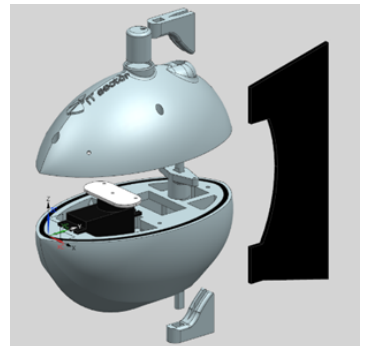

(a)

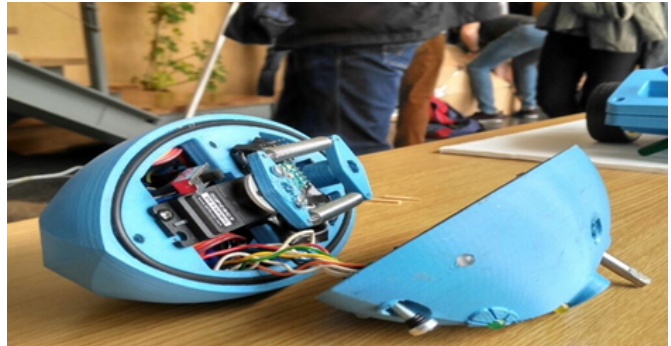

(b)

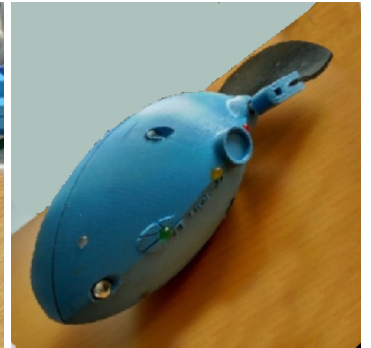

(c)

Fig. 4. Image of the biological inspired educational fish robot Bubbles. ${ }^{19}$

\section{Discussion}

One possible definition of engineering is "making what you need with the things you can get". Engineering is working with physical and financial constraints in order to create something useful. The main ethic question facing an engineer is that (s)he needs to act over the world. Many world transformations, small or big, sometimes with an importance and societal impact unrelated to their size were a consequence of engineering acts.${ }^{20}$ So, an engineer needs to act in order to change the world, but it needs to act with a limited knowledge, 
because the knowledge is limited - we are always finding things we did not knew. Besides the limited knowledge, the limited resources of our planet, and the need to share the resources with others (all the people on Earth), are also constraints that influence Ethics and also Engineering.

While attending the EPS@ISEP, students have to consider the ethical issues surrounding their product, and other more general ethics on a range of issues, in the Ethics and Deontology module. There are five critical points in relation with both ethical and deontological concerns, and are subject of attention in the Ethics and Deontology module, namely: Engineering, Marketing, Academics, Environmental and, finally, Liability ethics. It is essential for the development of the projects that each one of the topics mentioned are fully taken into consideration by the students when taking decisions. In some cases they encounter some ethical conflicts and difficulties in the process of developing, launching and selling a new product. These conflicts can often be very complicated, and to be able to find the right solution and have everyone's best interests at heart, it is needed a concrete set of ethics.

Regarding the ethical and deontological concerns faced by the students while developing the ornithopter, they dealt with engineering ethics, sales and marketing ethics, academic ethics, environmental ethics, liability aspects, and intellectual property rights.

Concerning the Bro-Fish development, the students considered the ethical issues surrounding their product and other general ethics implications. The ethics and deontological issues were considered in every decision they made, since the team believed that this would contribute to create a successful product and brand on the market.

Finally, and in relation to the development of Bubbles, the team considered that it was vital to follow the codes of environmental ethics and to perform it by carefully selecting the best available materials that do not endanger the natural world. This could be as simple as ensuring that every possible measure had been considered to attempt to reuse materials, and preventing the need for the creation of new components. Furthermore, to complete the creation of the didactic robotic fish they complied with the Toy Safety (2009/48/EC-200906-30) and the Waste Electrical and Electronic Equipment (2012/19/EC-2012-07-04) EU directives to ensure that it was legal to place Bubbles on the market and that it met the safety regulations.

\section{Conclusion}

This paper described the European Project Semester, a capstone programme offered by a network of European universities to engineering, project design and business undergraduates, and how this program (and in particular its implementations at the School of Engineering of the Polytechnic of Porto - EPS@ISEP), instils the ethical, deontological and sustainability dimensions of engineering project development in Bachelor students. With this purpose, was introduced the EPS programme and described its implementation at ISEP.

By analysing how students developing different projects addressed the ethical and deontological issues in their robotic projects developed within the programme, it was concluded that they were forced to consider these aspects in the prototypes they developed and, this way, have acquired sensitivity to these topics.

\section{Acknowledgements}

This work was partially financed by National Funds through the Portuguese funding agency, Fundação para a Ciência e a Tecnologia (FCT), within project UID/EEA/50014/2019. 


\section{References}

1. B. Stappenbelt, Ethics in engineering: Student perceptions and their professional identity development, Journal of Technology and Science Education 3, 3 (2013).

2. C. B. Fleddermann, Engineering ethics, 4 edn. (Prentice Hall, Upper Saddle River, USA, 2012).

3. B. K. Jesiek, Q. Zhu, S. E. Woo, J. Thompson and A. Mazzurco, Global engineering competency in context: Situations and behaviors, Online Journal for Global Engineering Education 8, 1 (2014), Available at: https://digitalcommons.uri.edu/ojgee/vol8/iss1/1.

4. Q. Zhu and B. K. Jesiek, Engineering ethics in global context: Four fundamental approaches, in 2017 ASEE Annual Conference 8 Exposition, Columbus, Ohio (ASEE 2017), (American Society for Engineering Education, 2017).

5. D. Bairaktarova and A. Woodcock, Engineering student's ethical awareness and behavior: A new motivational model, Science and Engineering Ethics 23, 1129(Aug 2017).

6. Engineering Council \& Royal Academy of Engineering, Statement of Ethical Principles for the Engineering Profession, tech. rep., EC \& RAE (March 2017), Available: http://www.engc. org.uk/professional-ethics. Last access on March 2019.

7. European Network for Accreditation of Engineering Education, EUR-ACE Framework Standards and Guidelines (EAFSG) Available: http://www .enaee.eu/wp-assets-enaee/uploads/ 2012/02/EAFSG_full_nov_voruebergehend.pdf, (2015), Last access on May, 5, 2019.

8. Engineering Council, The Accreditation of Higher Education Programmes: UK Standard for Professional Engineering Competence - Third edition Available: https://www.engc.org.uk/ standards-guidance/standards/uk-spec/, (2014), Last access on May, 5, 2019.

9. Accreditation Board for Engineering and Technology, Engineering Change: A Study of the Impact of EC2000 Available: http://www.abet.org/wp-content/uploads/2015/04/ EngineeringChange-executive-summary.pdf, (2006), Last access on May, 5, 2019.

10. Accreditation Board for Engineering and Technology, Going Global Accreditation Takes Off Worldwide - 2008 Annual Report For ABET Fiscal Year 2007-2008 Available: http://www. abet .org/wp-content/uploads/2015/04/2008-ABET-Annual-Report-.pdf, (2008), Last access on May, 5, 2019.

11. Engineers Australia, Stage 1 Competency Standard For Professional Engineer Available: https://www.engineersaustralia.org.au/resource-centre/resource/ stage-1-competency-standard-professional-engineer, (2013), Last access on May, 5, 2019.

12. Royal Academy of Engineering, High ethical standards promoted by engineering profession (2017), Available: https://www.raeng.org.uk/news/news-releases/2017/july/ high-ethical-standards-promoted-by-engineering-pro. Last access on July 2019.

13. A. Andersen, The European Project Semester: A Useful Teaching Method in Engineering Education, in Project Approaches to Learning in Engineering Education: The Practice of Teamwork, eds. L. C. de Campos, E. A. T. Dirani, A. L. Manrique and N. van Hattum-Janssen (SensePublishers, Rotterdam, 2012), Rotterdam, pp. 15-28.

14. A. Andersen, Preparing engineering students to work in a global environment to co-operate, to communicate and to compete, European Journal of Engineering Education 29, 549 (2004).

15. B. Malheiro, M. Silva, M. C. Ribeiro, P. Guedes and P. Ferreira, The European Project Semester at ISEP: the challenge of educating global engineers, European J. of Eng. Ed. 40, 328 (2015).

16. B. Malheiro, P. Guedes, M. F. Silva and P. Ferreira, Fostering professional competencies in engineering undergraduates with eps@isep, Education Sciences 9 (2019).

17. B. Caramin, I. Dunn, R. Ney, Y. Klawikowski, A. J. Duarte, B. Malheiro, C. Ribeiro, F. Ferreira, M. F. Silva, P. Ferreira and P. Guedes, Design and implementation of a biologically inspired flying robot an EPS@ISEP 2014 spring project, in Proc. of the 3rd Int. Conf. on Technological Ecosystems for Enhancing Multiculturality (TEEM 2015), (ACM Press, 2015).

18. A. Ishii, M. Heibeck, M. Blazejewski, R. Nybjörk, A. J. Duarte, B. Malheiro, C. Ribeiro, F. Ferreira, M. F. Silva, P. Ferreira and P. Guedes, Design and implementation of a biologically inspired swimming robot an EPS@ISEP 2014 spring project, in Proc. of the 3rd Int. Conf. on Technological Ecosystems for Enhancing Multiculturality (TEEM 2015), (ACM Press, 2015).

19. A. Reinhardt, A. C. Esteban, J. Urbanska, M. McPhee, T. Greene, A. Duarte, B. Malheiro, C. Ribeiro, F. Ferreira, M. F. Silva, P. Ferreira and P. Guedes, Didactic robotic fish - an EPS@ISEP 2016 project, in Interactive Collaborative Learning, eds. M. E. Auer, D. Guralnick and J. Uhomoibhi (Springer International Publishing, Cham, 2017).

20. H. Petroski, To Forgive Design: Understanding Failure (The Belknap Press of Harvard University Press, Cambridge, Massachusetts, 2012). 